\title{
研究論文
}

\section{Processing of Irradiated Uranium Dioxide Fuel by Chlorination-distillation}

\author{
塩化物分留法による照射済み二酸化ウラン燃料の再処理 \\ By Takehiko ISHIHARA* and Kenmei HIRANO*
}

\begin{abstract}
Using the difference in vapor pressure between the chlorides of uranium and those of fission products, a chlorination-distillation process of irradiated uranium dioxide fuel was investigated. The experiments were carried out with the chlorination agent of $\mathrm{CCl}_{4}$ vapor flowing through a quartz reaction tube assembly at various reaction and condensation temperatures. On a single distillation, about $80 \%$ of the uranium is recovered and about $90 \%$ of the $\gamma$-emitting fission products is separated from the uranium. Main nuclides condensed together with the uranium are ${ }^{141} \mathrm{Ce}$ and ${ }^{144} \mathrm{Ce}$. For the purpose of improving the decontamination of uranium, natural $\mathrm{CeO}_{2}$ is mixed with the irradiated $\mathrm{UO}_{2}$ to the extent of $1 \%$ before chlorination. About $97 \%$ of fission products is separated from the uranium, and ${ }^{103} \mathrm{Ru},{ }^{106} \mathrm{Ru},{ }^{137} \mathrm{Cs}$ and ${ }^{147} \mathrm{Nd}$ remain as the residue.
\end{abstract}

\section{INTRODUCTION}

The chloride volatility process has been applied to the processing of irradiated nuclear fuel by some groups. Speeckaert ${ }^{(1)(2)}$ applied the method to hydrogenated uranium metal or alloy using chlorine gas. Gens ${ }^{(3)}$ tried to separate alloying elements from uranium alloy fuel by using hydrogen for pretreatment in the Zircex process.

The authors applied the method for the separation of uranium from irradiated uranium dioxide fuel, using $\mathrm{CCl}_{4}$ vapor as the chlorination agent. The results of the cold experiments with synthetic samples were reported previously ${ }^{(4)}$. The present report describes the results obtained with irradiated samples.

Pearlman ${ }^{(6)}$ and Smiley ${ }^{(6)}$ are said to have tried to process uranium carbide or dioxide fuel by using $\mathrm{CCl}_{4}$, but no detailed results have yet been published.

\section{Experimental}

The $\mathrm{UO}_{2}$ samples used were the pellets of $7.5 \mathrm{~mm}$ both in diameter and in height, and their chemical composition and porosity are given in Table 1 . The pellets were irradiated for 4 weeks in the JRR-1 reactor

Table 1 Chemical composition and porosity of $\mathrm{UO}_{2}$ pellet

\begin{tabular}{c|cc}
\hline $\begin{array}{c}\text { Chemical } \\
\text { composition }\end{array}$ & Content \\
\hline $\mathrm{UO}_{2}{ }^{\dagger}$ & $\min$. & $99.9 \%$ \\
$\mathrm{Ag}$ & $\max$. & $1 \mathrm{ppm}$ \\
$\mathrm{B}$ & $\max$. & $2 \prime \prime$ \\
$\mathrm{Al}$ & $\max$. & $150 \prime \prime$ \\
$\mathrm{C}$ & $\max$. & $100 \prime \prime$ \\
$\mathrm{Ca}$ & $\max$. & $50 \prime \prime$ \\
$\mathrm{Ti}$ & $\max$. & $50 \prime \prime$ \\
$\mathrm{Cd}$ & $\max$. & $1 \prime \prime$ \\
$\mathrm{Fe}$ & $\max$. & $300 \prime \prime$ \\
$\mathrm{Mo}$ & $\max$. & $100 \prime \prime$ \\
$\mathrm{Si}$ & $\max$. & $200 \prime \prime$ \\
\hline Porosity & $6.1 \pm 0.5 \%$ & \\
\hline$\dagger \mathrm{O}=2.00$ &
\end{tabular}

* 石原健彦、平野見明。Chem. Engng. Lab., Japan Atomic Energy Res. Inst. (日本原子力研究所 化学工学研究室) 
with an integrated flux of $1 \times 10^{16} \mathrm{n} / \mathrm{cm}^{2}$. After letting the activity decay for about a month to a year, they were pulverized to 5 $\sim 10 \mu$ by milling. The samples used in one run ranged in weight $50 \sim 200 \mathrm{mg}$.

The chlorination agent, $\mathrm{CCl}_{4}$, was of the reagent grade. Argon gas dried through a $\mathrm{CaCl}_{2}$ column was used for dilution and sweeping of the $\mathrm{CCl}_{4}$ vapor.

The experimental apparatus used was the same as that for the cold experiments already reported $^{(4)}$. It was a tubular assembly made of transparent quartz, and the temperatures in the reaction tubes were electrically controlled. Fig. 1 shows the apparatus schematically. The temperatures of three furnaces were named $T_{1}, T_{2}$ and $T_{3}$, and the reaction tube inserted in them, No. 1, 2 and 3, from left to right in Fig. 1 . Table 2 shows the dimensions of these reaction tubes.

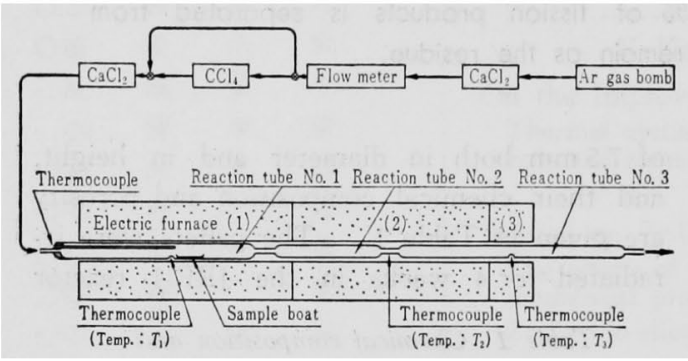

Fig. 1 Experimental apparatus

Table 2 Dimensions of reaction tubes

\begin{tabular}{c|c|c}
\hline No. & $\begin{array}{l}\text { Internal } \\
\text { diameter (mm) }\end{array}$ & Length (mm) \\
\hline 1 & 26 & 390 \\
2 & 20 & 190 \\
3 & 20 & 405 \\
\hline
\end{tabular}

The irradiated $\mathrm{UO}_{2}$ were chlorinated by the flowing $\mathrm{CCl}_{4}$ vapor, and the chlorides formed were fractionally distillated just after the chlorination. The condensed chlorides in the three tubes were dissolved in nitric acid, and the resultant solutions were analyzed chemically or $\gamma$-spectrometrically. The uranium concentration was determined photometrically with $\mathrm{H}_{2} \mathrm{O}_{2}$, and the quantity of fission products was determined by scintillation counting. The fission product nuclides were identified by $\boldsymbol{\gamma}$-ray spectrometry.

\section{Results}

\section{Recovery of uranium}

Fig. 2 shows the fractions of uranium remained or condensed in the three tubes, No. 1, 2 and 3 under the conditions of $T_{1}$ : $600^{\circ} \mathrm{C}, T_{2}: 160^{\circ} \sim 310^{\circ} \mathrm{C}$ and $T_{3}$ : room temperature (about $25^{\circ} \mathrm{C}$ ). No uranium is found to remain in Tube No. 1. Most of the uranium recovered are found to be condensed in Tube No. 2 and it is affected very little with the temperature $T_{2}$. The fraction condensed in Tube No. 3 decreases when $T_{2}$ falls in the range beyond $250^{\circ} \mathrm{C}$, the total recovery being more than $95 \%$.

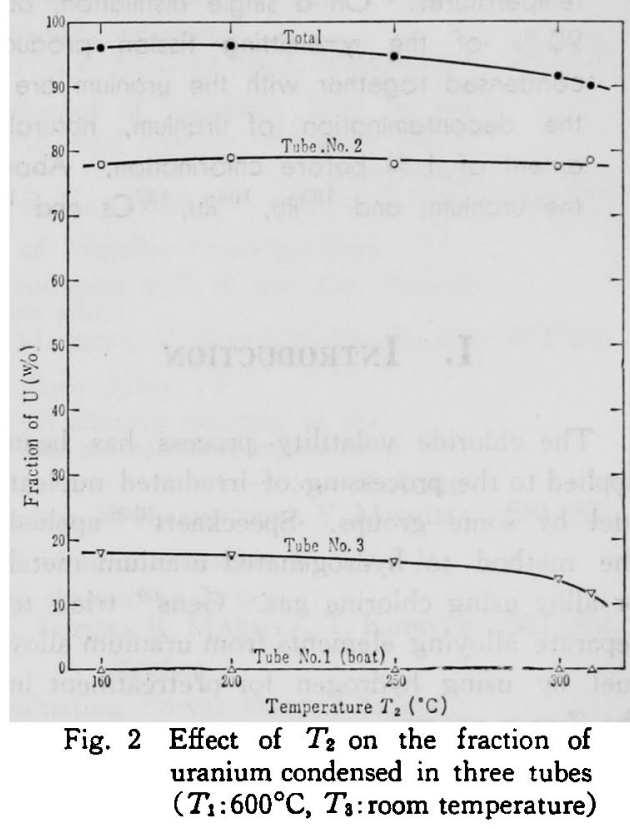

In the following experiments but that of Fig. $5, T_{2}$ was fixed to $250^{\circ} \mathrm{C}$.

No effect of decay time on the recovery of uranium is found as shown in Fig. 3.

\section{Behavior of fission products}

Fig. 4 shows the $\gamma$ activity fractions of fission products remained or condensed in the three tubes, No. 1, 2 and 3 under the coditions of $T_{1}: 600^{\circ} \mathrm{C}, T_{2}: 250^{\circ} \mathrm{C}$ and $T_{8}$ : room temperature (about $25^{\circ} \mathrm{C}$ ). The fractions of fission products are found to depend on the decay time of samples. The fractions of 


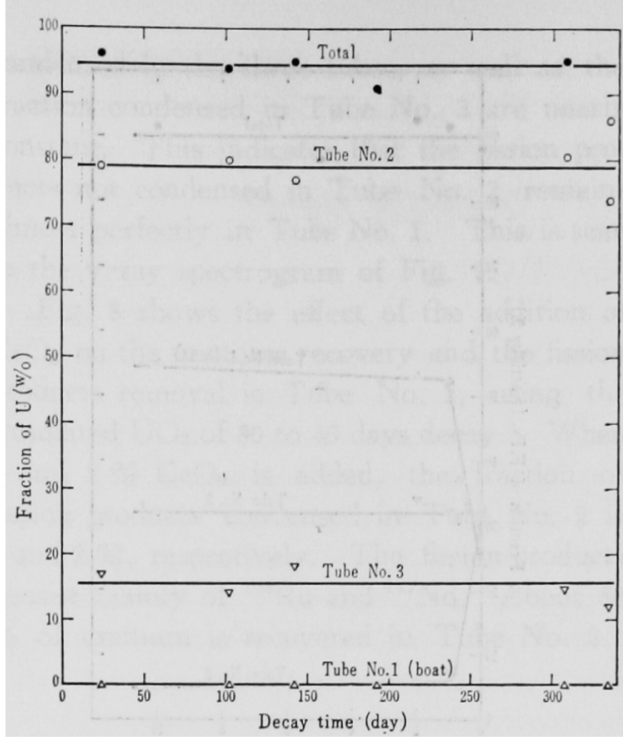

Fig. 3 Effect of decay time on the fraction of uranium condensed in three tubes $\left(T_{1}: 600^{\circ} \mathrm{C}, T_{2}: 250^{\circ} \mathrm{C}, T_{3}\right.$ : room temperature)

fission products remained or condensed in Tubes No. 1 and 2 show minima at the decay time of about 140 and 100 days, respectively, and the fraction in Tube No. 3 show maximum at the decay time of about 150 days.

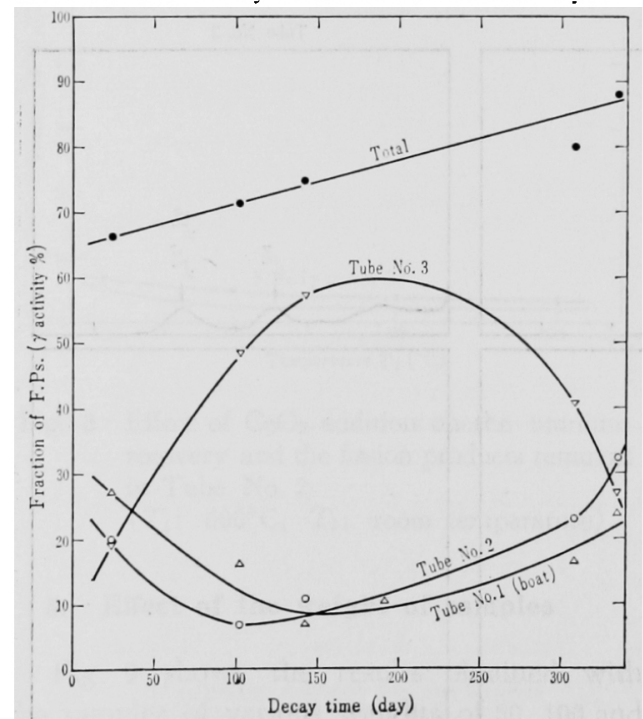

Fig. 4 Effect of decay time on the fraction of fission products condensed in three tubes

$\left(T_{1}: 600^{\circ} \mathrm{C}, T_{2}: 250^{\circ} \mathrm{C}, T_{3}:\right.$ room temperature)

Fig. 5 shows the $\gamma$ activity fractions of fission products remained or condensed in the three tubes with the samples of 100 days decay.
The fraction of fission products is the least in Tube No. 2 where most of the uranium is condensed, and about $50 \%$ of the fission products is condensed in Tube No. 3 together with the remaining uranium. The fraction of fission products in Tube No. $I$ is not affected by the temperature $T_{2}$, whereas the fractions in Tubes No. 2 and 3 decrease with increasing $T_{2}$. The composition of condensates in Tube No. 2 is the most favorable to recover uranium decontaminated from fission products, especially with $T_{2}$ in the high temperature range.

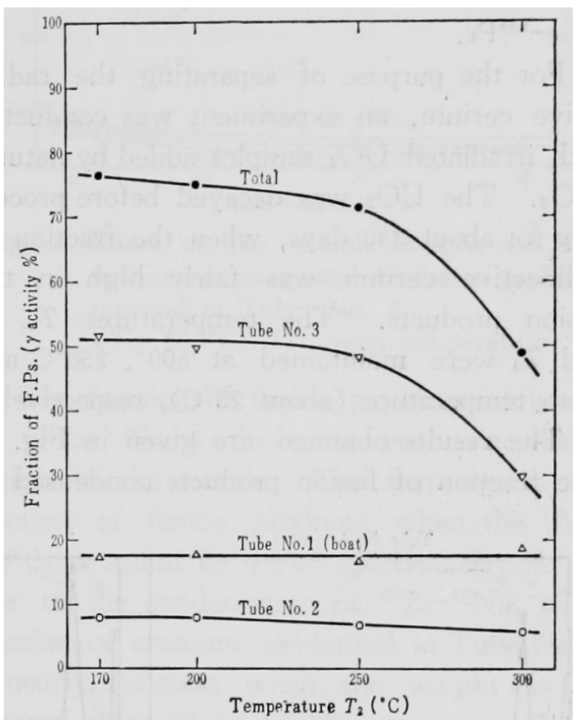

Fig. 5 Fraction of fission products remained or condensed in three tubes ( $T_{1}: 600^{\circ} \mathrm{C}, T_{3}$ : room temperature)

\section{Fission product nuclides condensed in Tube No.2}

Table 3 shows the main fission product nuclides condensed in Tube No. 2. The kind of nuclides depends on the decay time of the irradiated samples. When decayed for 1

Table 3 Main nuclides of fission products condensed in Tube No, 2

\begin{tabular}{c|c}
\hline $\begin{array}{c}\text { Decay time } \\
\text { (day) }\end{array}$ & Main nuclides \\
\hline 30 & ${ }^{103} \mathrm{Ru},{ }^{141} \mathrm{Ce},{ }^{144} \mathrm{Ce}-{ }^{144} \mathrm{Pr},{ }^{147} \mathrm{Nd}$ \\
02 & ${ }^{103} \mathrm{Ru},{ }^{141} \mathrm{Ce},{ }^{144} \mathrm{Ce}^{-144} \mathrm{Pr}$ \\
142 & ${ }^{103} \mathrm{Ru},{ }^{137} \mathrm{Cs},{ }^{141} \mathrm{Ce},{ }^{144} \mathrm{Ce}-144 \mathrm{Pr}$ \\
234 & ${ }^{106} \mathrm{Ru}-1{ }^{106} \mathrm{Rh},{ }^{137} \mathrm{Cs},{ }^{141} \mathrm{Ce},{ }^{144} \mathrm{Ce}-{ }^{144} \mathrm{Pr}$ \\
335 & ${ }^{106} \mathrm{Ru}-106 \mathrm{Rh},{ }^{137} \mathrm{Cs},{ }^{144} \mathrm{Ce}{ }^{-14} \mathrm{Pr}$ \\
\hline
\end{tabular}


month to 1 year, main nuclides condensed are invariably ${ }^{141} \mathrm{Ce}$ and ${ }^{144} \mathrm{Ce}^{-144} \mathrm{Pr}$; in the earlier part of the decay time, other minor nuclides condensed are ${ }^{103} \mathrm{Ru}$ and ${ }^{147} \mathrm{Nd}$, and in the later part ${ }^{106} \mathrm{Ru}^{106} \mathrm{Rh}$ and ${ }^{137} \mathrm{Cs}$.

\section{Effect of the addition of natural cerium dioxide}

From the results obtained, it is concluded that it is not possible to separate most of the fission products from irradiated $\mathrm{UO}_{2}$ by simple fractional distillation after chlorination. The fission products condensed with uranium in Tube No. 2 consist mainly of ${ }^{141} \mathrm{Ce}$ and ${ }^{144} \mathrm{Ce}^{-144} \mathrm{Pr}$.

For the purpose of separating the radioactive cerium, an experiment was conducted with irradiated $\mathrm{UO}_{2}$ samples added by natural $\mathrm{CeO}_{2}$. The $\mathrm{UO}_{2}$ was decayed before processing for about 330 days, when the fraction of radioactive cerium was fairly high in the fission products. The temperatures $T_{1}, T_{2}$ and $T_{3}$ were maintained at $600^{\circ}, 250^{\circ} \mathrm{C}$ and room temperature (about $25^{\circ} \mathrm{C}$ ), respectively.

The results obtained are given in Fig. 6. The fraction of fission products condensed in

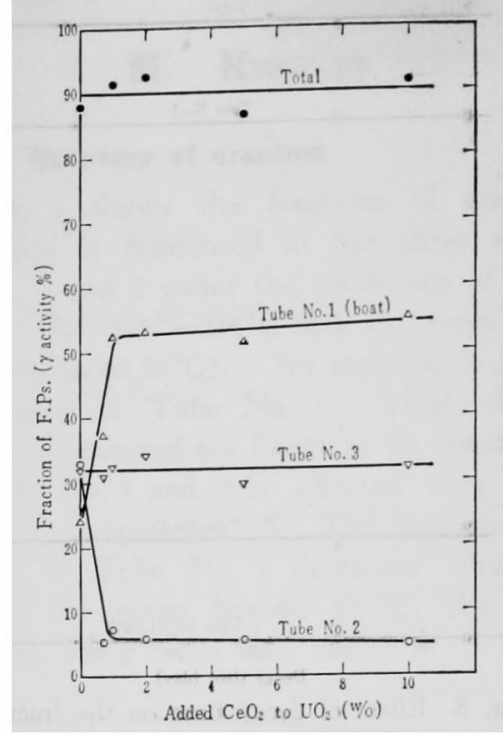

Fig. 6 Effect of $\mathrm{CeO}_{2}$ addition on the fission products distillation

Tube No. 2 decreases down to $6 \%$ by addition of $1 \%$ or more of $\mathrm{CeO}_{2}$ powder. In any range of the addition of $\mathrm{CeO}_{2}$, the sum of the fractions of fission products remained or
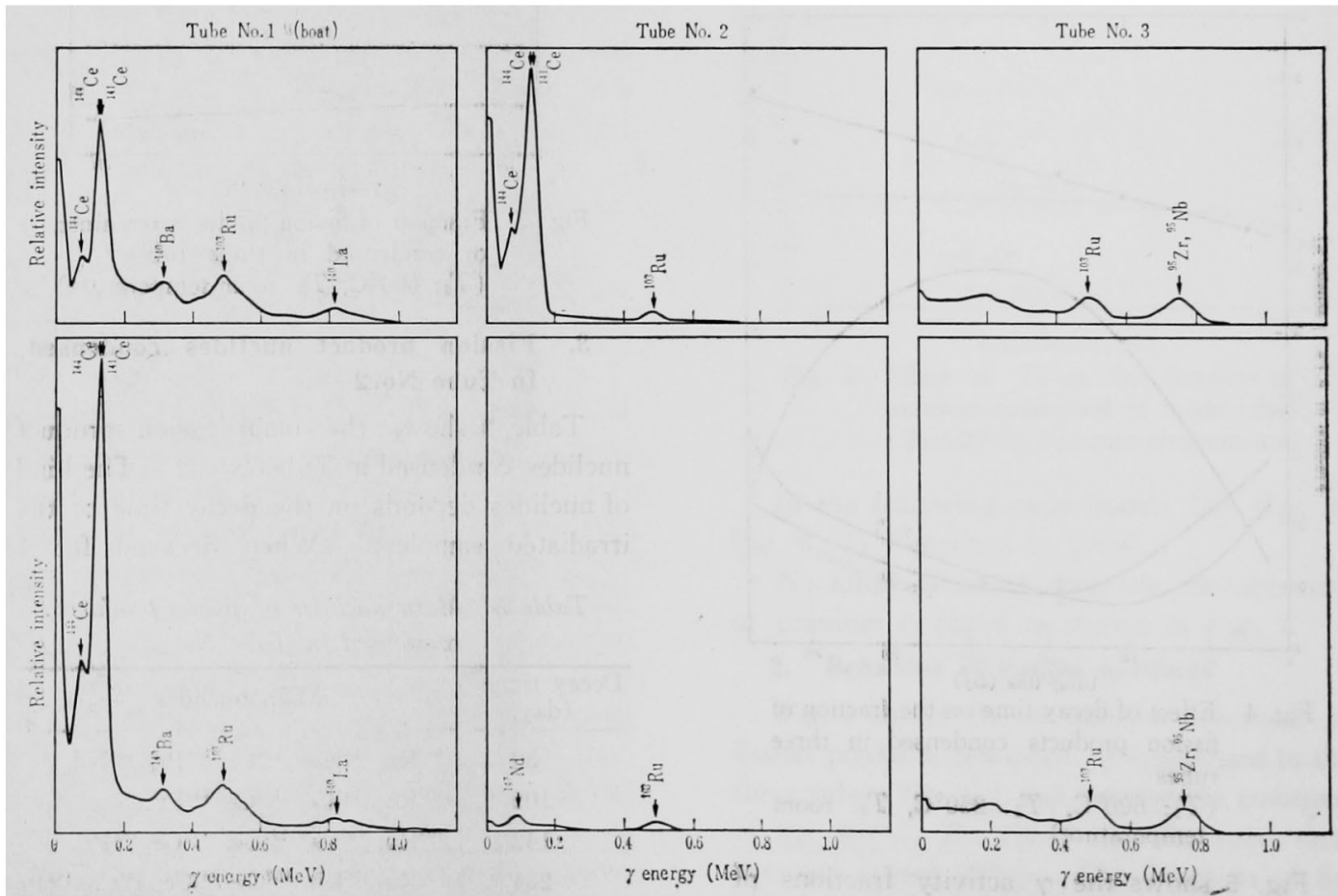

Fig. $7 \gamma$ spectrogram of fission products remained or condensed in three tubes (Upper curves: no $\mathrm{CeO}_{2}$ addition; Lower curves: $1 \% \cdot \mathrm{CeO}_{2}$ addition) 
condensed in the three tubes, as well as the fraction condensed is Tube No. 3 are nearly constant. This indicates that the fission products not condensed in Tube No. 2: remains almost perfectly in Tube No. 1. This is seen in the $\gamma$-ray spectrogram of Fig. 7 .

Fig. 8 shows the effect of the addition of $\mathrm{CeO}_{2}$ on the uranium recovery and the fission products removal in Tube No. 2, using the irradiated $\mathrm{UO}_{2}$ of 30 to 45 days decay. When 1 and $2 \% \mathrm{CeO}_{2}$ is added, the fraction of fission products condensed in. Tube No. 2 is 4 and $2 \%$, respectively. The fission products consist mainly of ${ }^{103} \mathrm{Ru}$ and ${ }^{147} \mathrm{Nd}$. About 80 $\%$ of uranium is recovered in Tube No. 2.

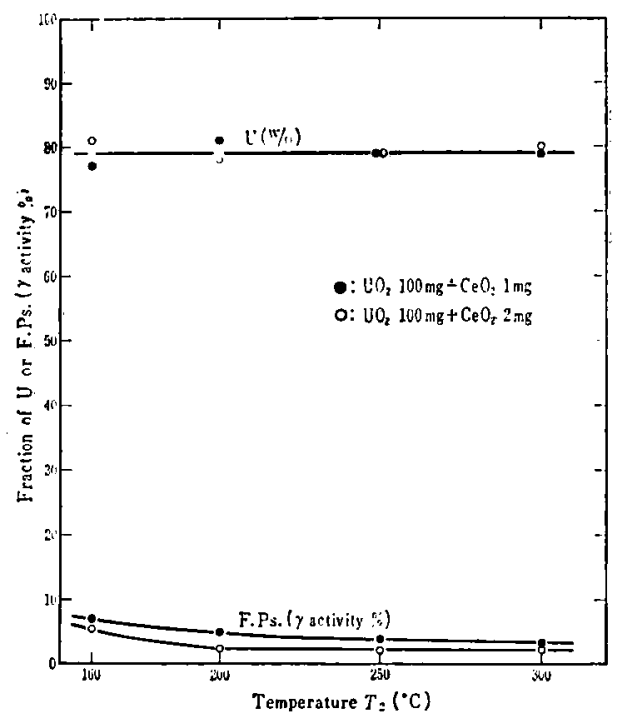

Fig. 8 Effect of $\mathrm{CeO}_{2}$ addition on the uranium recovery and the fission products removal in Tube No. 2

$\left(T_{1}: 600^{\circ} \mathrm{C}, T_{3}:\right.$ room temperature)

\section{Effect of the weight of samples}

Fig. 9 shows the results obtained with the samples of various weights of 50,100 and $200 \mathrm{mg}$.

The fraction of $\mathrm{CeO}_{2}$ added was $1 \%$ in each case, and the temperatures $T_{1}$ and $T_{3}$ were fixed to $600^{\circ} \mathrm{C}$ and room temperature (about $25^{\circ} \mathrm{C}$ ), respectively, and the $T_{2}$ to $160^{\circ}, 200^{\circ}, 250^{\circ}$ or $300^{\circ} \mathrm{C}$. The decay time of the samples ranged $30 \sim 45$ days.

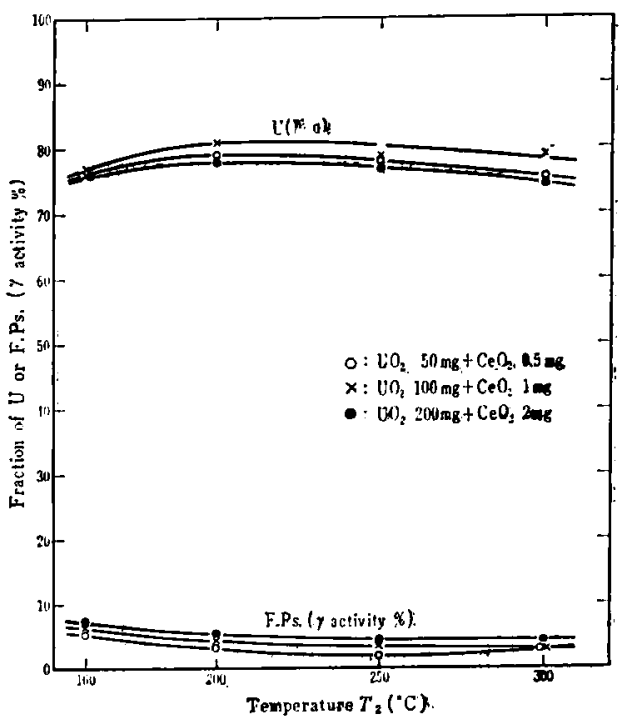

Fig. 9 Effect of the sample weight on the uranium recovery and the fission products removal in Tube No. 2

( $T_{1}: 600^{\circ} \mathrm{C}, T_{3}$ : room temperature)

The fraction of fission products condensed in Tube No. 2 decreases with decreasing weight of the sample. The increase in the fraction of fission products, when the $T_{2}$ is $160^{\circ} \mathrm{C}$, is found by $\gamma$-ray spectrometry to be due to the condensation of ${ }^{95} \mathrm{Zr}^{-95} \mathrm{Nb}$. The fraction of uranium condensed in Tube No. 2 Iis nearly constant when the weight is increased from $50 \mathrm{mg}$ to $200 \mathrm{mg}$.

\section{Discussion}

As mentioned in the previous report ${ }^{(4)}$, it is desirable to simplify the process and to increase the decontamination factor as much as possible, even at the sacrifice of uranium recovery to some extent.

As it is rather difficult to increase the percentage of recovery of uranium to more than $95 \%$, efforts are focused to minimize the fission products in Tube No. 2 as much as possible.

In the range of decay time $30 \sim 45$ days, ${ }^{103} \mathrm{Ru},{ }^{141} \mathrm{Ce},{ }^{144} \mathrm{Ce}-{ }^{-144} \mathrm{Pr},{ }^{147} \mathrm{Nd}$, etc., condense in Tube $\mathrm{No}$. 2; however, when natural $\mathrm{CeO}_{2}$ is added, ${ }^{141} \mathrm{Ce}$ and ${ }^{144} \mathrm{Ce}^{-144} \mathrm{Pr}$ are almost completely separated, and the fission products $(\gamma)$ condensed consist mainly of ${ }^{103} \mathrm{Ru}$ and 
${ }^{147} \mathrm{Nd}$. In the longer decay time, ${ }^{103} \mathrm{Ru}$ and ${ }^{147} \mathrm{Nd}$ decay out rapidly, and the fission products $(\gamma)$ condensed are mainly ${ }^{106} \mathrm{Ru}^{-106} \mathrm{Rh}$ and ${ }^{137} \mathrm{Cs}$ with long half-lives.

The results for the irradiated samples may be compared with those obtained with synthetic samples ${ }^{(4)}$. All fission products whose vapor pressures in the form of chlorides are larger than that of $\mathrm{UCl}_{4}$, are almost perfectly separated as expected. The problem remained is the separation of fission products, such as cerium, whose vapor pressures in the form of chlorides are lower than that of $\mathrm{UCl}_{4}$.

Large quantities of cerium are condensed together with uranium in Tube No. 2, except in the case of $\mathrm{CeO}_{2}$ addition, and this is caused by the following fact. The fission products formed with 4 weeks of irradiation in JRR-1 $\left(1 \times 10^{16} \mathrm{n} / \mathrm{cm}^{2}\right)$ are of about $0.7 \mathrm{ppm}$ in weight of the uranium, and the amount of cerium is below $0.1 \mathrm{ppm}$. This corresponds to less than $1 / 10^{4}$ of the amount added to the synthetic sample, $2 \%{ }^{(4)}$. By the addition of natural $\mathrm{CeO}_{2}$, the relative abundance of active cerium condensed is considered to be decreased markedly. The effect of the addition is now being studied in detail.

At $600^{\circ} \mathrm{C}$, barium almost completely remained in the boat: this is due to the fact that the vapor pressure curve of $\mathrm{BaCl}_{2}$ lies in the higher temperature side (more than $100^{\circ} \mathrm{C}$ ) of that of $\mathrm{CeCl}_{3}$ and that, at $600^{\circ} \mathrm{C}$, the vapor pressure of $\mathrm{BaCl}_{2}$ is fairly lower than that of $\mathrm{CeCl}_{3}$.

It was deduced in the previous report ${ }^{(4)}$ that the separation of cesium and cadmium from uranium should be difficult. In the present experiment, it was observed that cesium could not be separated from uranium. Cadmium was failed to be detected in any tube, and this may be due to the fact that only a trace amount of cadmium was produced in the irradiated uranium.

Ruthenium was detected in every tube of the apparatus. This will be because ruthenium gives several types of chlorides, such as $\mathrm{RuCl}$, $\mathrm{RuCl}_{2}, \mathrm{RuCl}_{3}, \mathrm{RuCl}_{4}$ and $\mathrm{RuCl}_{5}$, and their vapor pressures differ from each other.

Neodimium was detected in Tube No. 2; the reason will be that the vapor pressure curve of $\mathrm{NdCl}_{3}$ lies in the lower temperature side of that of $\mathrm{CeCl}_{3}$ and at the same temperature $\mathrm{NdCl}_{3}$ has higher volatility than $\mathrm{CeCl}_{3}$.

In the present experiment, the fraction of uranium condensed in Reaction tube No. 2 was $78 \sim 79 \%$ and the decontamination factor of $\gamma$-emitting fission products was about 40 . When any additional processing should be applied for the recovery of uranium condensed in Tube No. 3, this chlorination-distillation process may become a promising process for short-cooled $\mathrm{UO}_{2}$ fuel.

The authors wish to express their thanks to Dr. Yutaka Yamamoto and $\mathrm{Mr}$. Toshio Honda of the Chem. Engng. Lab., JAERI, for their encouragement and helpful suggestions given in the course of this study.

(The present report was orally presented at the Autumn Meeting of the Japan Inst. of Metals, in Akita, on Oct. 18, 1961 and at the 3 rd National Nucl. Congress, in Tokyo, on Feb. 14, 1962.)

(Received June 30, 1962)

\section{- REFERENCE- -}

(1) P. SPEeckaert: BLG-38, (AEC-tr-4549), (1959).

(2) P.SPEECKAERT: $C E N-R-1015$, (AEC-tr-4553), (1960).

(3) T. A. Gens, R. L. Jolley: ORNL-2992, (1961).

(4) T. Ishihara, K. Hirano, T. Honda: This Journal, 4, No. 4, 231 (1962).

(5) Anon.: Reactor Fuel Processing, 3, No. 3, 29 (1960).

(6) W. G. SMILEY: NAA-SR-5350, $\pi-10$, (1960). 